\title{
Implementasi Affirmative Action Dalam Rekrutmen Dan Seleksi Bintara Polri Di Polda Papua 2019
}

\author{
Noach Hendrik Daud Dwaa') \\ 1) Program Pascasarjana Ilmu Administrasi, Fakultas Ilmu Administrasi, Universitas \\ Indonesia, Indonesia \\ Eko Prasojo ${ }^{2)}$ \\ 2) Program Pascasarjana Ilmu Administrasi, Fakultas Ilmu Administrasi, Universitas \\ Indonesia, Indonesia
}

Diterima Februari, 2020; Disetujui April, 2020; Dipublikasikan Juni, 2020

\begin{abstract}
Abstrak
Tujuan kajian ini adalah menganalisis hasil penerapan tindakan afirmatif selama proses rekrutmen beserta seleksi Kepolisian di Papua, sehingga realisasi kompetensi Polri yang sesuai dengan standar akan menghasilkan kinerja profesional yang baik untuk organisasi. Metode penelitian menggunakan metode post-positivisme. Hasil penelitian menunjukkan bahwa pelaksanaan affirmative action selama rekrutmen beserta seleksi calon Non-commissioning Officer di Polda Papua masih belum optimal, di mana perekrutan dan seleksi petugas Polri di Polda Papua, Orang Asli Papua (OAP) atau Ras Melanesia lebih cenderung mengambil alih Penduduk Asli Non-Papua. Fungsi tindakan afirmatif dari sistem rekrutmen dan seleksi di Kepolisian Daerah Papua adalah tempat perubahan yang diharapkan untuk menyelesaikan pembangunan di Papua. Kapolri juga meminta agar merit system yang diterapkan dapat meningkatkan motivasi Penduduk Asli Papua untuk mendaftar sebagai calon Pejabat Non-Nomisi dan dapat mendukung tindakan afirmatif yang diambil melalui perekrutan dan seleksi dengan merit system yang akan meminimalkan hubungan kelompok yang akan didiskriminasi oleh organisasi yang menggunakan non-bantuan atau terkait dengan kelompok atau ras tertentu.
\end{abstract}

Kata kunci: Petugas non-Komisi, Tindakan Afirmatif, Sumber Daya Manusia, Polisi

\section{Abstract}

The purpose of this research is to analyze the results of the application of affirmative action in the recruitment and selection of the Police in Papua, so that the realization of Polri competencies that are in accordance with the standards will produce good professional performance for the organization. The research method uses the post-positivism method. The results showed that the implementation of affirmative action in the recruitment and selection of prospective Non-commissioned Officer in the Papua Regional Police was still not optimal, where the recruitment and selection of Polri officers in the Papua Regional Police, the Papuan Native (OAP) or the Melanesian Race were more likely to take over the Non Papuan Native. The affirmative action function of the recruitment and selection system within the Papua Regional Police is a place of change that is expected to complete development in Papua. The Chief of Police also requested that the merit system applied be able to increase Papuan Native motivation to register as a candidate for Non-commissioned Officer and be able to support optimal, affirmative action taken through recruitment and selection with a merit system that would minimize the group relations that would be discriminated against by organizations using non-assistance or related to certain groups or races.

Keywords : Non-commissioned Officer, Affirmative Action, Human Resources, Police

How to Cite: Dwaa, D.H.N. \& Prasojo, E. (2020). Implementasi Affirmative Action dalam Rekrutmen dan Seleksi Bintara Polri di Polda Papua 2019. PUBLIKAUMA: Jurnal Ilmu Administrasi Publik UMA, 8 (1): 4049 



\section{PENDAHULUAN}

Tuntutan menciptakan kinerja yang semakin berkualitas merupakan bentuk konsekuensi dari keberadaan profesionalisme. Selain itu, tidak mengesampingkan aspek moralitas personel dalam melaksanakan tugas (Raharjo \& Angkasa, 2011). Tindakan profesional cenderung mengupayakan tercapainya suatu kinerja yang diharapkan sesuai dengan standar atau penilaian dari organisasi maupun pengguna jasa atau masyarakat (Carlan \& Lewis, 2009). Meskipun kinerja polisi memiliki standar yang telah dibuat oleh institusi tersebut, namun faktanya penilaian variabel kesuksesan personil kepolisian selama pelaksanaan tugas pokok yakni berupa kompetensi agar personil polisi dapat profesional dalam pelaksanaan tugas didukung dengan penilaian masyarakat terhadap kinerja polisi itu sendiri (Loftus \& Price, 2016). Hal ini juga berlaku pada institusi Kepolisian Negara Republik Indonesia, dimana kompetensi Polri yang sesuai standar akan menghasilkan profesionalisme kinerja yang baik bagi organisasi. Dalam pemenuhan kebutuhan personil kepolisian berpangkat brigadir, Kapolri melalui lembaga Kepolisian Republik Indonesia melaksanakan perekrutan secara bertahap. Pada pelaksanaannya, Kapolri mendeligasikan kewenangan kepada Kapolda dan jajaran melalui seleksi penerimaan Brigadir Polri yang dilaksanakan di Kepolisian Daerah. Hal ini dilaksankan untuk memenuhi standar rasio jumlah personel Polri sesuai dengan daftar susunan personel (Austriani et al., 2016).

Pengelolaan sumber daya manusia (SDM) kepolisian secara profesional merupakan salah satu misi kepolisian dalam pencapaian tujuan. Tujuan tersebut adalah terwujudnya pemeliharaan keamanan dan ketertiban masyarakat (Harkantibmas) sehingga dapat mendorong meningkatnya motivasi kerja guna mencapai kesejahteraan dalam organisasi maupun output dari organisasi
(Inga, 2016). Misi tersebut menjadi dasar upaya membina SDM kepolisian di Indonesia. Misi dalam bentuk pembinaan SDM diawali dengan menerapkan komitmen terhadap kualitas rekrutmen dan seleksi anggota Polri yang tepat sejak awal perekrutan yang berbasis merit system. Kajian sebelumnya menyebutkan bahwa sistem perekrutan berbasis merit system merupakan opsi terbaik, yang menerapkan prosedur terbuka, terdapat analisis kompetensi (substansi dan teknis), serta tidak ada kriteria terbaik selain merit system dalam perekrutan personil organisasi baik di publik mupun privat (Berman et al., 2001; Zaman, 2015). Berkenaan dengan kajian tersebut, maka diharapkan penerapan merit system selama rekrutmen beserta seleksi anggota Polri yang tepat, dapat menghasilkan personil Polri yang unggul sehingga dapat mendukung pelaksanaan tugas-tugas Polri sebagai pengemban fungsi keamanan dalam negeri (Hollyer, 2009; Roberts \& Hill, 1941; Sylvia \& Meyer 2002; Zaman, 2015). Dalam konteks manajemen SDM, maka hal ini merupakan bentuk penyiapan dan pelaksanaan strategi koordinatif dalam menjamin optimalisasi kebermanfaatan SDM dalam pencapaian tujuan institusi (Desseler, 2004; Hasibuan, 2006; Huselid et al., 1997; Irianto, 2001; Sofyandi, 2008).

Merit system pada dasarnya menggambarkan suatu sistem yang memungkinkan seseorang untuk mencapai keberhasilan secara proporsional dengan bakat dan kemampuan, dimana bertujuan untuk mengembangkan pegawai atau anggota sehingga memiliki kompetensi yang sesuai dan dapat mewujudkan tujuan organisasi dengan optimal (Aronson, 1950). Meskipun merit system belum secara eksplisit tersebutkan dalam regulasi (UU Nomor 2/2002), namun secara prinsip telah diturunkan dalam Roadmap Reformasi Birokrasi Polri Gelombang 3 Tahun 2016-2019 Bab 3c poin $6 \mathrm{~b}$ tentang penguatan sistem SDM 
dengan menggunakan merit system. Upaya tersebut berpeluang melahirkan transisi yang lebih baik dalam aspek kemajuan budaya kepolisian yang bermula dari pembangunan SDM secara terpadu dan berkelanjutan. Bukan hanya membebankan profesionalisme aparatur pada aparat pelaksana, tetapi juga harus diawali dari pengambil kebijakan dan aktor penyusun strategi secara objektif serta menghilangkan subjektivitas. Jika Polri mampu melaksanakan manajemen rekrutmen beserta seleksi SDM Polri yang berkualitas, maka probabilitas dalam meningkatkan budaya kepolisian yang lebih baik (profesional, taat hukum, bermoral, dan modern) pada masyarakat demokratis akan sangat mungkin terlaksana secara optimal.

Sistem perekrutan beserta seleksi personil Polri di Papua dilakukan dengan dua model. Model pertama yaitu rekrutmen dan seleksi Orang Asli Papua (OAP), dan; model kedua berupa rekrutmen dan seleksi Non Orang Asli Papua (Non-OAP). Selama rekrutmen dan seleksi personil berlangsung, jumlah kelulusan OAP atau Ras Melanesia lebih sedikit sehingga menampakkan adanya kontras yang terjadi dan ada anggapan diskriminatif. Fenomena tersebut memunculkan tuntutan masyarakat dan lembaga-lembaga masyarakat seperti MRP, DPRD, dan LSM di Papua dalam bentuk desakan pada Polri meningkatkan jumlah lulusan OAP sebagai anggota Polri sehingga terhindar dari rasa terdiskriminasi terhadap OAP. Oleh karena itu, dibutuhkan sistem yang mendukung anti diskriminasi terhadap setiap individu selama perekrutan dan seleksi melalui Affirmative Action. Affirmative Action sejalan dengan prinsip-prinsip dan nilai keadilan sosial. Prinsip dan nilai Affirmative Action memiliki potensi dan peluang dalam menjembatani masalah sosial budaya yang muncul, sekaligus menjamin representasi dan proporsi SDM secara ideal di karakteristik kependudukan, geografi, dan budaya masyarakat pada organisasi, baik publik atau privat (Gomez, 2003). Dengan kebijakan afirmasi, maka diharapkan dapat meningkatkan jumlah minat pendaftar calon anggota Polri oleh masyarakat OAP untuk berpartisipasi selama perekrutan dan seleksi calon anggota Polri oleh BIRO SDM Polda Papua. Hal tersebut salah satunya bermuara dalam menghasilkan calon anggota Polri OAP dari berbagai daerah di Provinsi Papua, dalam dukungannya terhadap percepatan pembangunan SDM di Papua. Berdasar pada kajian, maka tujuan kajian ini adalah melakukan deskripsi dan analisis penerapan Affirmative Action dalam perekrutan beserta seleksi Bintara Polri OAP (Ras Melanesia) dan Non-OAP di Polda Papua serta mendeskripsikan apakah penerapan Affirmative Action dapat memotivasi pendaftaran calon Bintara Polri OAP (Ras Melanesia) di Polda Papua.

\section{METODE PENELITIAN}

Metode riset kualitatif dengan pendekatan studi kasus merupakan metode yang digunakan untuk menganalisis Affirmative Action dalam perekrutan beserta seleksi bintara Polri di Polda Papua tahun 2019 serta dampak dari penerapan Affirmative Action. Penulis menggunakan pendekatan post-positivism selama menganalisis kasus terkait. Pendekatan tersebut menerangkan bahwa kaum post-positivis mengaplikasikan filsafat deterministik dan keyakinan penyebab (kausatif) sebagai pendorong akibat (Creswell, 2017). Penggunaan pendekatan postpositivis dalam kajian ini memiliki tujuan analisis mendalam pada penerapan Affirmative Action selama perekrutan beserta seleksi bintara Polri di Polda Papua tahun 2019 beserta dampak dari penerapan Affirmative Action terhadap minat pendaftar. 


\section{HASIL DAN PEMBAHASAN}

Implementasi Affirmative Action dalam rekrutmen dan seleksi Bintara Polri Orang Asli Papua (Ras Melanesia)

Rekrutment merupakan suatu proses yang dilakukan oleh organisasi untuk mencari personil yang memenuhi standar syarat tertentu sesuai dengan kebutuhan organisasi. Secara konseptual, perekrutan personil adalah upaya pencarian personil dan mendorong serta memberikan peluang yang seluas-luasnya kepada seseorang untuk mengisi formasi yang tersedia dalam sebuah organisasi. Sedangkan proses seleksi merupakan lanjutan dari perekrutan personil dalam institusi atau organisasi, yang bertujuan untuk memilih calon personil Polri yang tepat dan berkualitas melalui beberapa tahapan seleksi yang telah ditentukan sesuai dengan kebutuhan organisasi (Jamin, 1995).

Proses rekrutmen dan seleksi selalu dilaksanakan setiap tahunnya untuk meningkatkan jumlah personil Polri sebagai kebutuhan organisasi Polri sesuai dengan anggaran yang tersedia. Seperti di wilayah lainnya, Polda Papua melakukan rekrutmen dan seleksi personil Polri dengan membagi dua kelompok yaitu calon anggota Polri OAP dan calon anggota Polri Non-OAP. Menurut SK Kapolda Papua Nomor.Kep/308/VII/2019 tentang Penentuan Kelulusan Akhir Peserta Penerimaan Calon Bintara Polri antara OAP dan Non-OAP tahun 2019 di Polda Papua, dijelaskan bahwa yang dimaksud peserta OAP adalah peserta dengan orang tua kandung (Bapak dan Ibu) OAP dan/atau salah satu dari Bapak/Ibu kandung adalah OAP. Berikut ini adalah data minat masyarakat daerah Papua dalam melaksanakan pendaftaran sebagai calon anggota Bintara Polri Ras Melanesia (OAP) dan bukan Ras Melanesia (NonOAP).
Tabel 1. Minat Pendaftar dan Kelulusan Bintara Polri Tahun 2019

\begin{tabular}{c|c|c|c|c|c}
\hline No & Th. & \multirow{2}{*}{$\begin{array}{c}\text { Jumlah } \\
\text { Pendaftar }\end{array}$} & \multicolumn{3}{|c}{$\begin{array}{c}\text { Masuk Pendidikan/Lolos } \\
\text { Seleksi }\end{array}$} \\
\cline { 4 - 6 } & & & Non-OAP & OAP & Jumlah \\
\hline 1 & 2019 & 2.972 & 145 & 112 & 257 \\
\hline
\end{tabular}

Sumber. Data Biro SDM Polda Provinsi Papua (2019)

Berdasarkan data yang ada, dinyatakan bahwa OAP atau Ras Melanesia lebih sedikit yang lulus dibandingkan Non-OAP. Angka tersebut menjadi dasar tuntutan masyarakat dan lembaga masyarakat seperti MRP, DPRD, dan LSM di Papua mendesak Polri agar dapat memperbanyak lulusan OAP sehingga terhindar dari rasa terdiskriminasi terhadap OAP. Berdasarkan data pendidikan Bintara Polri 2019, calon yang dinyatakan lulus seleksi berjumlah: polisi laki-laki adalah reguler 7.832, kompetensi khusus 411, talent scouting 104, ppkt/wilayah perbatasan 88, gagal calon taruna Akpol 40 sehingga total 8475 sedangkan polisi wanita: reguler 279 , kompetensi khusus 56, talent scouting 53, ppkt/wilayah perbatasan 6 , gagal calon taruna Akpol 6, sehingga total Polwan 400. sehingga jumlah keseluruhan calon anggota Polri yang lulus rekrutmen dan seleksi menjadi anggota Polri berpangkat Bintara pada tahuan 2019 adalah 8.875 orang dari seluruh daerah di Indonesia berdasarkan Surat Keputusan kuota dik Bintara Nomor kep/1317/VII/2019. Sehingga dari total 8.875 orang terdapat hanya ada 1,3\% OAP dari Polda Papua yang lulus seleksi menjadi anggota Polri pada tahun 2019.

Tabel 2. Minat Pendaftar dan Kelulusan Bintara Polri Tahun 2014-2019

\begin{tabular}{|c|c|c|c|c|c|c|c|c|}
\hline \multirow{3}{*}{ Th. } & \multirow{3}{*}{$\begin{array}{c}\text { Jml } \\
\text { Penda } \\
\text { ftar }\end{array}$} & \multicolumn{6}{|c|}{ Masuk Pendidikan/Lolos Seleksi } & \multirow{3}{*}{$\begin{array}{c}\text { Tota } \\
\text { l }\end{array}$} \\
\hline & & \multicolumn{3}{|c|}{ Laki-laki } & \multicolumn{3}{|c|}{ Perempuan } & \\
\hline & & $\begin{array}{l}\text { Non- } \\
\text { OAP }\end{array}$ & OAP & $\begin{array}{c}\text { Juml } \\
\text { ah } \\
\mathbf{1 0 0} \\
\% \\
\end{array}$ & $\begin{array}{l}\text { Non- } \\
\text { OAP }\end{array}$ & OAP & $\begin{array}{c}\text { Jumla } \\
\text { h } \\
100 \%\end{array}$ & \\
\hline $\begin{array}{c}201 \\
4 \\
\end{array}$ & 6.353 & $\begin{array}{l}374 / \\
68 \% \\
\end{array}$ & $\begin{array}{l}180 / \\
32 \% \\
\end{array}$ & 554 & $\begin{array}{c}93 / \\
51 \% \\
\end{array}$ & $\begin{array}{c}92 / \\
49 \% \\
\end{array}$ & 185 & 739 \\
\hline $\begin{array}{c}201 \\
5\end{array}$ & 3.835 & $\begin{array}{l}211 / \\
60 \%\end{array}$ & $\begin{array}{l}139 / \\
40 \%\end{array}$ & 350 & $\begin{array}{l}37 / \\
64 \%\end{array}$ & $\begin{array}{c}21 / \\
36 \%\end{array}$ & 58 & 408 \\
\hline $\begin{array}{c}201 \\
6 \\
\end{array}$ & 3.172 & $\begin{array}{c}83 / \\
31 \% \\
\end{array}$ & $\begin{array}{l}187 / \\
69 \% \\
\end{array}$ & 270 & $\begin{array}{c}6 / \\
32 \% \\
\end{array}$ & $\begin{array}{c}13 / \\
68 \% \\
\end{array}$ & 19 & 289 \\
\hline $\begin{array}{c}201 \\
7 \\
\end{array}$ & 3.257 & $\begin{array}{l}196 / \\
59 \% \\
\end{array}$ & $\begin{array}{l}137 / \\
41 \% \\
\end{array}$ & 333 & $\begin{array}{c}6 / \\
46 \% \\
\end{array}$ & $\begin{array}{c}7 / \\
54 \% \\
\end{array}$ & 13 & 346 \\
\hline $\begin{array}{c}201 \\
8 \\
\end{array}$ & 1.631 & $\begin{array}{l}262 / \\
73 \% \\
\end{array}$ & $\begin{array}{r}99 / \\
27 \% \\
\end{array}$ & 361 & $\begin{array}{c}6 / \\
37 \% \\
\end{array}$ & $\begin{array}{l}10 / \\
63 \% \\
\end{array}$ & 16 & 377 \\
\hline $\begin{array}{c}201 \\
9 \\
\end{array}$ & 2.972 & $\begin{array}{l}139 / \\
57 \% \\
\end{array}$ & $\begin{array}{l}105 / \\
43 \% \\
\end{array}$ & 244 & $\begin{array}{c}6 \\
46 \% \\
\end{array}$ & $\begin{array}{c}7 / \\
54 \% \\
\end{array}$ & 13 & 257 \\
\hline $\begin{array}{c}\text { Juml } \\
\text { ah }\end{array}$ & 18.248 & $\begin{array}{c}1.265 \\
/ \\
60 \% \\
\end{array}$ & $\begin{array}{r}\mathbf{8 4 7} / \\
40 \% \\
\end{array}$ & $\begin{array}{c}2.11 \\
2\end{array}$ & $\begin{array}{l}\mathbf{1 5 4} / \\
51 \% \\
\end{array}$ & $\begin{array}{l}150 / \\
49 \% \\
\end{array}$ & 304 & $\begin{array}{c}2.41 \\
6\end{array}$ \\
\hline
\end{tabular}

Sumber. Data Biro SDM Polda Provinsi Papua tahun 2019 
Berdasarkan Inpres Nomor 9 Tahun 2017, Instruksi Presiden Republik Indonesia Nomor 9 Tahun 2017 Tentang Percepatan Pembangunan Kesejahteraan Di Provinsi Papua dan Provinsi Papua Barat, yang kemudian dilanjutkan oleh Kepolisian Republik Indonesia untuk mendukung penuh terhadap peningkatan SDM dalam rekrutmen Polri di Polda Papua, Kapolri mengeluarkan beberapa kebijakan yang tercantum dalam Surat Pengumuman Kapolri Nomor PENG/4/III/DIK.2.1./2019 per 5 Maret 2019 tentang Penerimaan Terpadu Bintara Polri T.A. 2019. Kebijakan Kapolri yakni: pertama, sumber rekrutmen terdiri dari bintara regular, bintara kompetensi khusus, bintara talent scouting, bintara ppkt/wilayah perbatasan, bintara yang tidak lulus sebagai taruna Akpol di tingkat pusat, dan; kedua, syarat fisik (tinggi badan) berupa calon pendaftar umum (pria dengan tinggi badan $165 \mathrm{~cm}$ dan wanita 160 $\mathrm{cm}$ ) serta Ras Melansesia di Polda Papua dan Papua Barat (daerah asal pesisir, pria dengan tinggi badan $163 \mathrm{~cm}$ dan wanita $165 \mathrm{~cm}$; daerah asalh pegunungan, pria dengan tinggi badan $160 \mathrm{~cm}$ dan wanita $155 \mathrm{~cm}$ ). Polda Papua mendapat perlakuan khusus bagi OAP dalam rekrutment dan seleksi calon Bintara Polri tahun 2019, karena syarat tinggi badan calon anggota Polri ras melanesia dapat dikurangi. Sehingga, seharusnya jumlah bintara Polri dari OAP bertambah dan tanpa diskriminasi, karena peraturan pemerintah yang ingin mempercepat pengembangan papua dan putra putri asli Papua.

Perihal adanya pengurangan tinggi badan dalam persyarataran pendaftaran calon Bintara, terdapat beberapa permasalahan antara lain: Pertama, kurangnya sosialisasi kebijakan Affirmative Action oleh Polda Papua terkait tinggi badan tersebut berupa pengurangan tinggi badan yang disesuaikan dengan karakteristik OAP. Sehingga, banyak putra putri daerah Papua yang kurang berminat untuk mendaftar sebagai Bintara Polda Papua; Kedua, lokasi pendaftaran di Polda Papua yang terletak di Jayapura, sementara kemampuan ekonomi calon pendaftar yang minim. Hal ini menjadikan motivasi dalam mengikuti rekrutmen dan seleksi cenderung rendah, dan; Ketiga, pemberlakuan sistem online belum sepenuhnya mampu diaplikasikan mengingat fasilitas koneksi internet yang belum sepenuhnya merata. Hal ini kemudian, juga menjadi kendala teknis yang menurunkan motivasi OAP dalam mengikuti rekrutmen dan seleksi calon Bintara di Polda Papua.

Sejatinya, menurut Castle (dalam Smit, 2006), strategi dan praktik mengembangkan SDM melalui tindakan afirmatif harus menekankan perencanaan, induksi, sosialisasi dan pendidikan dan pelatihan kompensasi yang sesuai dengan lingkungan pembangunan atau wilayah lokal. Sehingga, terbentuk motivasi yang lebih tinggi. Strategi yang dimaksud termasuk:

Pengembangan model perencanaan tenaga kerja untuk memandu seleksi, pengembangan, dan penilaian karyawan (termasuk spesifikasi pekerjaan dan kinerja secara terperinci), serta melakukan perencanaan wilayah rekrutmen dan seleksi yang terjangkau oleh masyarakat lokal;

Pelatihan kepemimpinan dan prestasi yang dirancang untuk merangsang individualitas dan ketegasan peserta, dan untuk mengembangkan manajemen resiko;

Menjembatani program pendidikan yang mempersiapkan individu atau kelompok kecil lulusan sekolah untuk masuk ke dalam tujuan organisasi dan lebih fokus pada pembinaan sesuai budaya dan kemampuan lokal. Sehingga, pengambilan keputusan dan pemecahan masalah keterampilan serta prinsip-prinsip dasar organisasi dapat dipahami secara efektif dan efisien;

Program pelatihan dan bimbingan untuk mempersiapkan anggota berpotensi besar untuk peran manajemen, dan;

Penempatan awal manajer dari kelompok yang sama dan dianggap sebagai satu kesatuan dari kondisi budaya asli yang membuat mereka lebih cocok.

\section{Fungsi Affirmative Action dan Motivasi Calon Personil Polri}

Affirmative Action adalah kebijakan yang bertujuan agar kelompok/golongan tertentu mendapat kesetaraan dan kesamaan peluang antar kelompok/golongan lain dalam bidang relevan. Hal ini termasuk proses perekrutan beserta seleksi Polri di Papua. Kompleksitas masalah di Papua yang rumit dan fundamental mendorong stakeholder untuk menyusun Perpres Nomor 65 Tahun 2011 tentang Percepatan Pembangunan Provinsi Papua dan Provinsi Papua Barat (P4B) dan Perpres Nomor 66 Tahun 2011 tentang Unit 
Percepatan Pembangunan Provinsi Papua dan Provinsi Papua Barat (UP4B). UP4B memiliki tugas pokok: "Memberikan dukungan kepada Presiden Republik Indonesia dalam koordinasi, sinkronisasi, fasilitasi serta pengendalian dan evaluasi pelaksanaan program percepatan pembangunan di Provinsi Papua dan Papua Barat".

Adanya tindakan afirmatif pada sistem rekrutmen dan seleksi di tubuh Polda Papua, menjadi suatu perubahan yang diharapkan dapat mempercepat pembangunan di Papua. Kapolri juga berharap merit system yang diterapkan dapat meningkatkan motivasi OAP untuk mendaftar sebagai calon Bintara dan dapat bertugas secara optimal. Saat ini, meritokrasi sering digunakan sebagai konotasi yang positif untuk menggambarkan sistem sosial yang memungkinkan orang untuk mencapai keberhasilan secara proporsional dengan bakat dan kemampuan mereka. Tindakan afirmatif yang diwujudkan melalui rekrutmen dan seleksi dengan merit system akan meminimalisir pembentukan "kelompok" dalam kelompok yang merasa didiskriminasi dari organisasi berdasarkan kemampuan mereka yang kurang memadai, atau berkaitan dengan kelompok atau ras tertentu.

Padahal, menurut Johnson dan Redmond (dalam Smit, 2006) menyatakan adanya hubungan yang terkait antara motivasi kinerja dengan pelaksanaan merit system pada suatu organisasi. Lebih lanjut, Bredell (dalam Smit, 2006) menyatakan bahwa kinerja pekerjaan seseorang terutama tergantung pada dua aspek, yaitu kemampuan dan motivasi. Kemampuan mengacu pada potensi individu untuk berhasil menyelesaikan tugas atau pekerjaan. Motivasi adalah sebuah kekuatan pendorong internal yang mengaktifkan dan memberi energi pada individu dan yang mengarahkan perilakunya sedemikian rupa sehingga tujuan dapat dicapai. Kanter (1997) berpendapat bahwa ketika orang berada diberdayakan untuk berkontribusi, mereka ingin diberi penghargaan khusus untuk keberhasilan yang telah dicapai. Motivasi dan motif adalah dua kata yang saling berhubungan secara etimologis, motif dalam bahasa inggris motive, berasal dari kata motion, yang berarti gerakan. Menurut Suryabrata (dalam Kristanto \& Hary, 2015) motif adalah keadaan dalam setiap pribadi individu yang mendorong individu tersebut untuk melakukan aktivitas-aktivitas khusus dalam pencapaian tujuan tertentu. Selain motif, dalam psikologi juga dikenal istilah motivasi. Berawal dari kata motif itulah maka motivasi dapat diartikan sebagai proses sadar dalam mempengaruhi tingkah laku individu agar tergerak hatinya untuk melakukan sesuatu sehingga akan mencapai hasil ataupun juga tujuan tertentu.

Selanjutnya, Johnson dan Redmond (dalam Smit, 2006) memperjelas bahwa orang yang berbagi budaya dan latar belakang cenderung membentuk kelompok atau "dalam kelompok" dan dengan cara ini mereka memperoleh informasi melalui jaringan di luar selain sumber formal, atau dengan kata lain, adanya bias kelompok dan tujuan organisasi. Sehingga, apabila dikaitkan dengan pendaftaran bintara Polri di Papua, dapat dipahami perlu adanya tindakan afirmatif untuk meningkatkan motivasi kinerja di lingkungan Polda Papua, terutama untuk pendaftaran calon Bintara Polri sebagai titik manajerial yang penting, dalam upaya menghindari bias tujuan organisasi akibat sistem patronase. Bintara sendiri memiliki tugas dan peran sebagai konektor antara tingkat tertinggi (perwira) dengan terendah (tamtama) secara teknis. Biasanya bintara melatih aparat menjadi lebih professional, sehingga kemampuan manajerial yang sesuai dengan karakter orang lokal sangat dibutuhkan. Apabila terdapat Non-OAP, maka perlu tindakan yang adil dengan menerapkan sistem edukasi lokal, sehingga orang yang mengalami kesulitan dalam komunikasi (karena masalah dengan bahasa, penglihatan, pendengaran, atau literasi) harus diberikan waktu untuk memahami dan menyerap ide dan prosedur sebelum bertugas sebagai Bintara di wilayah Papua tersebut.

Mengedepankan masyarakat lokal sama artinya dengan menjadikan birokrasi representatif berada pada konteks pola rekrutmen seseorang dalam posisi administrasi publik, utamanya pada kesamaan kesempatan dan keterwakilan asal penduduk. Birokrasi representatif berfokus pada keadilan komposisi demografis masyarakat untuk memediasi ketegangan demokrasi dan birokrasi sehingga menjawab permasalahan proporsi keterwakilan, pertimbangan unsur sosio-ekonomi, dan karakter kewilayahan masyarakat (Groeneveld \& Walle, 2010; 
Mustofa, 2011). Birokrasi representatif berkaitan dengan kemampuan menjalankan 3 fungsi utama (kekuatan, pengambil keputusan, dan manajemen) dalam menyelesaikan 6 persoalan yang menjadi target dari pemerintahan good governance. Fungsi utamanya yakni bureaucracy as a power (birokrasi berorientasi pada kinerja dalam mengakomodasikan kepentingan dan merepresentasikan kepentingan lokal) (Kingsley, 1944; Lind, 2016 McMahon, 1946); bureaucracy as equal opportunity (birokrasi mewadahi kepentingan publik dan mampu merumuskannya ke dalam keputusan manajerial) (Wilson, 1941; Alves da Silva, 2007; Dahlberg et al., 2008), dan; bureaucracy as diversity management (birokrasi meningkatkan performa sebagai manajer publik sesuai dengan kebutuhan dan perkembangan kekinian).

\section{Motivasi: Faktor Intrinsik-Ekstrinsik}

Kompleksitas permasalahan di Papua berkaitan dengan fenomena ketimpangan proporsi kelulusan personil Polri membutuhkan strategi mendorong minat calon pendaftar untuk mengikuti seleksi. Berkenaan dengan strategi, maka harus dilakukan pemetaan motivasi internal dan eksternal. Motivasi sendiri merupakan bagian dan proses dalam diri seseorang yang dapat dipengaruhi oleh berbagai faktor baik intrinsik atau ekstrinsik. Menurut Wahjosumidjo (dalam Kuddy, 2017), faktor berpengaruh pada motivasi berupa faktor intrinsik (dari dalam individu) dan faktor ekstrinsik (dari luar individu). Faktor intrinsik berupa sikap terhadap aktivitas kerja, bakat diri, minat, kepuasan, pengalaman, dan lain-lain serta faktor dari luar individu yang bersangkutan seperti pengawasan, gaji, lingkungan kerja dan kepemimpinan (Widiastuti et al., 2018). Berdasarkan uraian tersebut, disimpulkan bahwa motivasi adalah upaya sadar memengaruhi tingkah laku individu untuk berbuat dan mencapai hasil atau tujuan guna mempertahankan hidupnya, dimana individu melakukan suatu kinerja ditentukan oleh faktor internal maupun faktor eksternal.

Dalam menyusun strategi meningkatkan minat bergabung sebagai personil Polri, maka harus dipahami dimana letak ketertarikan dan alasan para personil atau calon personil dalam mengikuti seleksi atau rekrutmen. Pemahaman tersebut lebih tepatnya berangkat dari aspek pemetaan minat dan motivasi yang mendasari. Telah dijelaskan bahwa terdapat 2 faktor yakni faktor intrinsik dan ekstrinsik. Faktor intrinsik yang terdiri dari persepsi, harga diri, harapan pribadi, kebutuhan, keinginan, kepuasan kerja, dan prestasi, serta; faktor ekstrinsik yang terdiri dari jenis/sifat pekerjaan, kelompok, lingkungan organisasi, situasi lingkungan kerja dan gaji/pendapatan. Berdasarkan riset yang telah dilakukan, ditemukan bahwa terdapat faktor baik intrinsik maupun ekstrinsik yang mendasari masing-masing motivasi calon pendaftar. Dari segi motivasi intrinsik, aspek yang paling utama mendasari minat calon pendaftar adalah aspek kebutuhan dan harapan pribadi, sedangkan faktor ekstrinsik berdasar pada gaji dan organisasi lingkungan kerja.

Aspek kebutuhan dan harapan pribadi menjadi dasar utama calon pendaftar dalam mengikuti seleksi dan rekrutmen di Polda Papua. Aspek ini berpeluang menjadi strategi Berkaitan dengan tujuan kesatuan di Polri, maka kemudian hal ini menjadi kesempatan dalam meningkatkan loyalitas anggota yang secara khusus berasal dari Papua. Semangat Esprit de Corps yang ada di lembaga Polri harus dikuatkan melalui pemahaman akan kebutuhan dan harapan pribadi. Tentunya hal ini juga disesuaikan dengan visi dan misi yang ada di tubuh Kepolisian Republik Indonesia. Selain faktor intrinsik, faktor ekstrinsik berupa gaji dan organisasi lingkungan kerja merupakan aspek yang harus diperhatikan. Dalam konteks penguatan kinerja, tentunya hal ini sangat berdampak pada kualitas kinerja. Beban kerja dan resiko pekerjaan sebagai polisi yang tinggi harus diimbangi dengan kuatnya faktor pendorong dan menciptakan dampak yang signifikan khususnya dalam aspek kesejahteraan anggota.

\section{SIMPULAN}

Berdasar pada proses telaah dan analisis yang sudah dilakukan, maka beberapa kesimpulan yang diajukan yakni: Pertama, implementasi affirmative action dalam rekrutmen dan seleksi calon Bintara di Polda Papua belum optimal, dimana rekrutmen dan seleksi personil Polri di Polda Papua, OAP atau Ras Melanesia lebih sedikit yang lulus dibandingkan Non-OAP, hal ini yang membuat tuntutan masyarakat dan lembaga-lembaga 
masyarakat seperti MRP, DPRD, dan LSM di Papua mendesak Polri agar Polri dapat memperbanyak lulusan OAP untuk menjadi anggota Polri sehingga terhindar dari rasa terdiskriminasi terhadap OAP; kedua, fungsi tindakan afirmatif pada sistem rekrutmen dan seleksi di tubuh Polda Papua menjadi suatu perubahan yang diharapkan mempercepat pembangunan di Papua. Untuk itu, merit system yang diterapkan adalah bertujuan meningkatkan motivasi OAP dalam bergabung sebagai calon Bintara secara optimal. Tindakan afirmatif melalui rekrutmen dan seleksi dengan merit system diharapkan meminimalisir pembentukan kelompok dalam kelompok yang merasa didiskriminasi dari organisasi berdasarkan non kemampuan mereka, atau berkaitan dengan kelompok/ras tertentu, dan; ketiga, Sebagai konsekuensi dari keberadaan kehidupan yang bersifat komunal, maka terdapat beberapa suku tertentu yang anti terhadap pemerintah sehingga motivasi menurun hingga hilang motivasi bergabung sebagai anggota Polri. Untuk itu, berangkat dari mayoritas motivasi utama tersebut adalah faktor internal (kebutuhan dan harapan pribadi) dan faktor eksternal (gaji dan lingkungan organisasi bekerja), maka strategi yang harus diupayakan adalah pemenuhan dan peningkatan 4 aspek kebutuhan tersebut.

\section{DAFTAR PUSTAKA}

Alvarado, L. A. (2010). Dispelling the Meritocracy Myth: Lessons for Higher Education and Student Affairs Educators. The Vermont Connection, 31(1-2), 10-20. https://scholarworks.uvm.edu/tvc/vol31/is $\underline{\mathrm{s} 1 / 2 /}$

Aronson, A. H. (1950). Merit System Objectives and Realities. Buletin, 13(4), 3-19. https://www.ssa.gov/policy/docs/ssb/v13n 4/v13n4p3.pdf

Austriani, N. L., Erviantono, T., \& Purnamaningsih, E. (2016). Penerimaan Sumber Daya Manusia Brigadir Polri dalam Perspektif Governance (Studi Penerimaan Sumber Daya Manusia Kepolisian Daerah Bali Tahun Anggaran 2015). Jurnal Fakultas IImu Sosial dan Ilmu Politik Universitas Udayana, 1(1), 110.

https://ojs.unud.ac.id/index.php/citizen/art icle/view/21636

Berman, E., Bowman, J., West, J., \& Van Mart, M. R. (2001). Human Resource Management in Public Service: Paradoxes, Processes, and Problems. USA: Sage Publications, Inc.
Carlan, P. E., \& Lewis, J. A. (2009). Dissecting Police Professionalism: A Comparison of Predictors Within Five Professionalism Subsets. Police Quarterly, 12(4), 370-387. https://doi.org/10.1177/109861110934846 $\underline{9}$

Creswell, J. W. (2017). Research Design: Pendekatan Metode Kualitatif, Kuantitatif, dan Campuran. Yogyakarta: Pustaka Pelajar.

Gomes, F. C. (2003). Manajemen Sumber Daya Manusia. Yogyakarta: Andi.

Groeneveld, S., \& Walle, S. V. (2010). A Contingency Approach to Representative Bureaucracy: Power, Equal Opportunities and Diversity. International Review of Administrative Science, 239-258. https://doi.org/10.1177/002085230936567 $\underline{0}$

Herman, S. (2008). Manajemen Sumber Daya Manusia. Jakarta: Graha Ilmu.

Hollyer, J. R. (2009). Patronage or Merit? Bureaucratic Recruitment in $19^{\text {th }}$ and Early $20^{\text {th }}$ Century Europe. New York University Department of Politics, 1, 1-38. https://ssrn.com/abstract $=1657615$

Huselid, M. A., Jackson, S. E., \& Schuler, R. S. (1997). Technical and Strategic Human Resource Management Effectiveness as Determinants of Firm Performance. Academy of Management Journal, 40(1), 171-188. https://www.markhuselid.com/pdfs/article s/1997 AMI Technical and Strategic SHRM. $\underline{\text { pdf }}$

Inga, L. O. (2016). Pengembangan Kapasitas Kemampuan Anggota di Kepolisian Resor (Polres) Palu Sulawesi Tengah. e-Jurnal Katalogis, 4(1), 82-94. http://iurnal.untad.ac.id/iurnal/index.php/ Katalogis/article/view/6515

Irianto, J. (2001). Manajemen Sumber Daya Manusia. Surabaya: Insan Cendekia.

Jackson, S. E., \& Schuler, R. S. (1995). Understanding Human Resource Management in the Context of Organizations and Their Environments. Anna Rev. Psychol, 237-263. https://doi.org/10.1146/annurev.ps.46.020 195.001321

Kingsley, J. D. (1944). Representative Bureaucracy: An Interpretation of the British Civil Service. Yellow Springs: The Antioch Press.

Kuddy, A. (2017). Pengaruh Kepemimpinan, Motovasi dan Disiplin Kerja Terhadap Kinerja Pegawai pada Dinas Pertanian dan Ketahanan Pangan Provinsi Papua. Jurnal Manajemen \& Bisnis, Fakultas Ekonomi \& Bisnis, 1(2), 22-36.

Lind, N. S. (2016). Representative Bureaucracy. Global Encyclopedia of Public Administration, Public Policy, and Governance, 1- 
6. https: //doi.org/10.1007/978-3-31931816-5 656-2

Loftus, J., \& Price, K. (2016). Police Attitudes and Professionalism. Administrative Issues Journal: Connecting Education, Practice, and Research, Winter, 6(2), 53-73. Diakses dari http://www.jurnal.manuncen.ac.id/index.ph $\mathrm{p} / \mathrm{imb} / \mathrm{article} / \mathrm{view} / 8$

Malayu, S. H. (2006). Manajemen Sumber Daya Manusia. Jakarta: PT. Bumi Aksara.

Macmahon, A. W. (1946). Representative Bureucracy: An Interpretation of the British Civil Service by J. Donald Kingsley. The American Historical Review, 52(1), 129-132. https://doi.org/10.1086/ahr/52.1.129

Mustofa, A. (2011). Reformasi Administrasi: Pendekatan Birokrasi Representatif dalam Meningkatkan Performa Birokrasi. Jurnal Kalamsiasi, $\quad 4(2), \quad 141-154$ http://repository.unitomo.ac.id/id/eprint/2 $\underline{32}$

Raharjo, A., \& Angkasa. (2011). Profesionalisme Polisi dalam Penegakan Hukum. Jurnal Dinamika Hukum, 11(3), 389-401. Diakses dari

http://dinamikahukum.fh.unsoed.ac.id/inde x.php/IDH/article/download/167/115

Roberts, F. L., \& Hill, B. (1941). The Merit System in Relationship to Public Health Personnel. American Journal of Public Health, 31, 121126. https://www.ncbi.nlm.nih.gov/pmc/articles LPMC1531288/

Smit, P. K. (2006). The Effect of Affirmative Action on Employee Motivation in the Sandf. Department of Human Resource, Tswane University of Technology. Diakses dari http://tutvital.tut.ac.za:8080/vital/access/m anager/Repositorv/tut:3941

Sylvia, R. D., \& Meyer, C. K. (2002). Public Personnel Administration. California: Harcourt College Publishers.

Widiastuti, R., Sudharto, \& Suwandi. (2018). Pengaruh Kepemimpinan Kepala Madrasah dan Motivasi Kerja Terhadap Budaya Kerja Guru Madrasah Aliyah di Kecamatan Mranggen Kabupaten Demak. JMP Universitas PGRI Semarang, 7(3), 311-327. http://dx.doi.org/10.26877/imp.v7i3.3147

Zaman, M. S. (2015). Merit-Based Recruitment: The Key to Effective Public Administration in Bangladesh. Journal of Public Administration and Governance, 5(3), 96-119. https://doi.org/10.5296/ipag.v5i3.8216 